\title{
The Effect of Varied Visual Scaffolds on Engineering Students' Online Reading
}

\author{
Pao-Nan Chou and Hsi-Chi Hsiao \\ (The authors contributed equally to this paper) \\ Cheng Shiu University, Kaohsiung, Taiwan (R.O.C.)
}

\author{
pnchou@csu.edu.tw; hchsiao@csu.edu.tw
}

\begin{abstract}
The purpose of this study is to explore the effect of varied visual scaffolds on engineering students' online reading. One experimental study was conducted to fulfill the purpose. The study adopted a randomized post-test design. The independent variable was visual scaffold (two types of visual scaffolds: static and interactive scaffolds); the dependent variables were three criterion tests (identification, terminology, and comprehension test) measuring students' online reading performances. Ninety-four undergraduate students majoring in information sciences and technology from an American public university voluntarily participated in this study. The results of the study showed that two visual scaffolds effectively improved students' online reading for lower order cognitive process; the interactive scaffold can enhance students' lower and medium cognitive thinking.
\end{abstract}

Keywords: Visual scaffolds, Online learning, Experimental study, Online reading, Instructional Technology

\section{Introduction}

While engaging in knowledge acquisition in online learning environments, especially online text reading, students tend to be disoriented and face a cognitive load problem (Chen \& Dwyer, 2003). Under this situation, specific instructional scaffolds should be used to assist learners to comprehend large amount of information (Sharma \& Hannafin, 2007). Of those available scaffolds listed in the existing literature, visual scaffolds are regarded as an effective tool to support student learning because human beings are visually oriented (Dwyer, 2007; Norman, 2004).

According to Davis (2007), the text-based reading document is still a mainstream instructional material in online learning settings despite the availability of high technologies. As Chen and Dwyer (2003) pointed out, online instructors often employed hypermedia documents as reading materials to support student learning. In order to pursue better instructional effectiveness, high-quality design in online reading materials is necessary. However, whether or not embedding visual scaffolds can enhance students' online reading performance is worthy of exploration.

Material published as part of this publication, either on-line or in print, is copyrighted by the Informing Science Institute. Permission to make digital or paper copy of part or all of these works for personal or classroom use is granted without fee provided that the copies are not made or distributed for profit or commercial advantage AND that copies 1) bear this notice in full and 2) give the full citation on the first page. It is permissible to abstract these works so long as credit is given. To copy in all other cases or to republish or to post on a server or to redistribute to lists requires specific permission and payment of a fee. Contact Publisher@InformingScience.org to request redistribution permission.
For the background information discussed above, this study aims to explore the ininstructional effectiveness of different types of visual scaffolds embedded in online reading material. Engineering students were chosen as a targeted group. One control group with no visual scaffolds was created. Two visuals, static and interactive visual scaffolds, were 
developed in an experimental study and serve as two treatment groups. The online reading material was a website that imparts basic science knowledge about the human heart. A post-test, consisting of identification, terminology, and comprehensive tests, was used to measure students' online reading performance. Specifically, the purpose of the study is to evaluate the instructional effectiveness of two types of visual scaffolds for engineering students in an online reading environment.

\section{Theoretical Foundation}

\section{The Concept of Scaffolding}

Scaffolding is defined as "an adult controlling those elements of the task that are essentially beyond the learner' capacity, thus permitting him to concentrate upon and complete only those elements that are within his range of competence" (Wood, Bruner, \& Ross, 1976, p.9). A theoretical foundation behind scaffolding is Vygotsky's zone of proximal development, which emphasizes the role of social interaction in promoting cognitive development and bridging the gap between what learners actually know and potentially know (Sharma \& Hannafin, 2007). To date, scaffolding no longer restricts interactions between individuals. It has extended to technological tools and instructional techniques, which are often regarded as scaffolds (Puntambekar \& Hubscher, 2005). For example, Zumbach, Reimam, and Koch (2006) designed a feedback-based instructional technique to promote a higher-level thinking during online discussions.

\section{The Feature of Scaffold}

In online learning settings, Hill and Hannafin (2001) proposed four types of scaffolds - procedural, strategic, metacognitive, and conceptual scaffolds - which can be employed to support student learning. Procedural scaffolds assist learners to use online resources and to "clarify requirement and reduce cognitive load" (p. 45). Strategic scaffolds provide learners with alternative approaches to engage online tasks. Metacognitive scaffolds allow learners to "assess what they know and what to do as they learn" (p. 45). Conceptual scaffolds help learners digest online information and facilitate knowledge construction.

In directed distance learning environments (DDLEs), Sharma, Oliver, and Hannafin (2007) defined DDLEs scaffolds as "planned strategies and content structures that assist the learner in more efficiently and effectively processing and internalizing course materials" (p. 265). Basically, DDLEs scaffolds are instructional techniques that aim to improve students' learning performances in terms of knowledge acquisition.

Saye and Brush (2002) considered two scaffolds to exist in hypermedia learning environments: hard and soft scaffolds. Hard scaffolds are "static supports that can be anticipated and planned in advance based on typical student difficulties with a task" (p. 81). In contrast, soft scaffolds are "dynamic and situational...require teachers to continuously diagnose the understandings of learners and provide timely support based on student responses "(p. 82). These two types of scaffolds must be balanced according to learners' differences and types of learning (Sharama \& Hannafin, 2007).

Hadwin and Winne (2001) distinguished the difference between tacit and explicit scaffolds while creating a software tool called CoNote2. Tacit scaffolds are "tools that are intended to cue students to attend to aspects of their studying without explicitly directing or instructing those studying activities" (p. 322). Oppositely, explicit scaffolds serve as "templates that focused students' attention by identifying and requiring students to use specific processes" (Sharma \& Hannafin, 2007, p. 31).

Based on above discussion, the visual scaffolds designed in this study serve a conceptual, DDLEs, hard, and tacit scaffold in facilitating knowledge acquisition from online reading materials. 


\section{Methods}

\section{Research Participant}

Ninety-four undergraduate students majoring in information sciences and technology from an American public university voluntarily participated in this study. During implementation of the study, student participants were randomly assigned to one of three instructional treatments. Table 1 shows the distribution of participants across treatment groups.

Table 1 Distribution of Participants in Treatments

\begin{tabular}{ll}
\hline Treatment & Total \\
\hline T1: Control & 32 \\
T2: Static visual scaffold & 31 \\
T3: Interactive visual scaffold & 31 \\
Total & 94 \\
\hline
\end{tabular}

From Table 1, the distribution of participants was almost exactly balanced across treatment groups. In other words, the number of participants in each group nearly achieves an equal number, which is a prerequisite step for an experimental study (Yoder, 2008).

\section{Online Learning Material}

In this study, Dwyer's (1978) 2000-word heart content script is chosen as the reading material because (a) "it provides a hierarchy of several types of educational objectives extending from the learning of basic facts to complex problem solving..."(p. 34), (b) its outcome measurements reflect high reliability coefficients, and (c) its contents are not related to participants' courses of study, thereby, avoiding potential threats to internal validity in the experimental design. The original script was transformed into online hypertext material with or without provision of scaffolds.

\section{Online Learning Measurement}

Dwyer's three criterion tests are used to measure students' online reading performance after students complete the instructional treatments. Detailed descriptions of three tests are summarized as follows (Dwyer, 1978, pp.45-47):

(a) Identification test (measuring factual knowledge): This multiple-choice test (20 items) evaluates students' abilities to identify parts or positions of an object.

(b) Terminology test (measuring conceptual knowledge): This multiple-choice test (20 items) was designed to measure knowledge of specific facts, terms, and definitions.

(c) Comprehension test (measuring rule/principle knowledge): This multiple-choice test (20 items) was designed to measure a type of understanding in which the individual can use the information being received to explain some other phenomenon.

Table 2 shows the results of these three tests which used the Kuder-Richardson 21 (K-R 21) reliability test for analysis. Overall, the reliability coefficient ranges from 0.78 to 0.93 , indicating each criterion test has strong internal consistency (Nitko \& Brookhart, 2006). 
Table 2 Reliability Analysis for Criterion Tests

\begin{tabular}{lll}
\hline Measures & Number of Item & K-R 21 \\
\hline Identification & 20 & 0.84 \\
Terminology & 20 & 0.83 \\
Comprehension & 20 & 0.78 \\
Total & 60 & 0.93 \\
\hline
\end{tabular}

\section{Experimental Treatment}

Participants in all treatment groups receive the same reading material. A distinct difference among treatment groups is the provision for instructional scaffolds. The details are:

(a) Treatment 1 (Control group): In this treatment group, students only receive the hypertext reading material. In order to retain participants' reading attention, several concept maps, which summarize each Web page's main ideas, are provided.

(b) Treatment 2 (Static visual scaffold): In this treatment, several static images, which relate to reading contents, are inserted into the reading material.

(c) Treatment 3 (Interactive visual scaffold): In this treatment, several Flash animations, which combine static images and concept maps, are inserted into the reading material. When participants' mouse pointers move over one pink oval-shaped box in the animations, a related static image will appear on the screen.

\section{Research Hypotheses}

In this study, the independent variable was visual scaffold (two types of visual scaffolds: static and interactive scaffolds); the dependent variables were three criterion tests (identification, terminology, and comprehension test) measuring students' online reading performances. A research assumption is that students who receive interactive instruction may perform better than students who receive static instruction. A major research hypothesis is:

No significant differences exist in criterion tests among students receiving different instructional treatments

\section{Research Procedure}

When arriving in a computer lab, participants were randomly assigned into one of the instructional treatments. Subsequently, students should read the online reading material in a one-hour session. After completing the instructional presentation, students received an online test, which covers the three criterion tests described earlier.

\section{Data Analysis}

The Statistical Package for the Social Sciences (SPSS) software version 14 was used to complete data analysis. The collected data was analyzed by a statistical technique, One-Way Multivariate Analysis of Variance (MANOVA), whose purpose is to test for treatment group differences when two or more dependent variables are to be considered simultaneously. 


\section{Results \& Discussion}

\section{Descriptive Statistics}

Table 3 reports a summary of descriptive statistics regarding the criterion tests. On average, students obtained 13.44 points $($ S.D. $=4.97)$ in the identification test, 12.02 points $($ S.D. $=4.96)$ in the terminology test, 11.80 points (S.D. $=4.67$ ) in the comprehension test. Overall, students tended to score higher in the identification test and lower in the comprehension test. A feasible explanation of this phenomenon is that the requirement of lower order knowledge in the identification test allows students to obtain higher scores; the requirement of higher order knowledge in the comprehension test causes students to score lower.

Table 3 Overall Summary for Each Test

(Score in each test ranges from 0 to 20)

\begin{tabular}{lll}
\hline Measures & Mean & S.D. \\
\hline Identification & 13.44 & 4.97 \\
Terminology & 12.02 & 4.96 \\
Comprehension & 11.80 & 4.67 \\
\hline
\end{tabular}

Consideration of the different instructional treatments in each criterion test produces a summary of descriptive statistics appearing in Table 4. On average, students in Treatment 1 obtained 11.03 points (S.D. $=4.99$ ) in the identification test, 10.47 points (S.D. $=4.94)$ in the terminology test, 10.84 points (S.D. $=4.33$ ) in the comprehension test; students in Treatment 2 obtained 14.26 points (S.D. $=5.32)$ in the identification test, 12.19 points (S.D. $=5.24)$ in the terminology test, 11.58 points (S.D. $=5.08$ ) in the comprehension test; students in Treatment 3 obtained 15.10 points (S.D. $=3.58$ ) in the identification test, 13.45 points (S.D. $=4.33$ ) in the terminology test, 13.00 points (S.D. $=4.49$ ) in the comprehension test.

Table 4 Summary of Treatment for Each Test (Score in each test ranges from 0 to 20)

\begin{tabular}{llll}
\hline Measures & $\begin{array}{l}\text { Treatment 1 } \\
\text { (Mean/S.D.) }\end{array}$ & $\begin{array}{l}\text { Treatment 2 } \\
(\text { Mean/S.D.) }\end{array}$ & $\begin{array}{l}\text { Treatment 3 } \\
(\text { Mean/S.D.) }\end{array}$ \\
\hline Identification & $11.03 / 4.99$ & $14.26 / 5.32$ & $15.10 / 3.58$ \\
Terminology & $10.47 / 4.94$ & $12.19 / 5.24$ & $13.45 / 4.33$ \\
Comprehension & $10.84 / 4.33$ & $11.58 / 5.08$ & $13.00 / 4.49$ \\
\hline
\end{tabular}

Based on the results in Table 4, Figure 1 shows graphic representations of instructional treatments for each criterion test. Overall, students in Treatment 3 (interactive visual scaffold) performed better than other two treatment groups. However, whether or not significant differences exist in each criterion test among three treatment groups still requires further information from the results of MANOVA analysis (inferential statistics). 


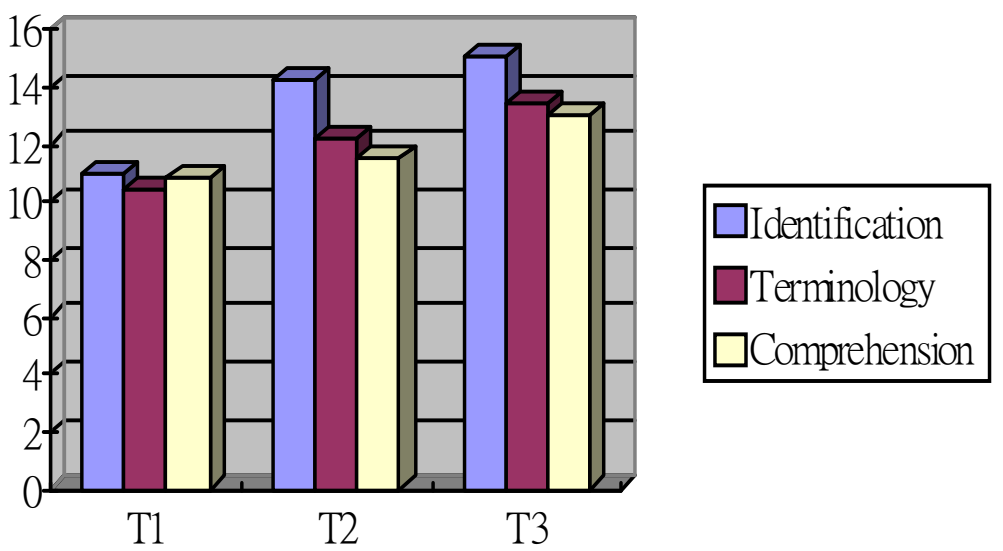

Figure 1 Means per treatment for each test

\section{Inferential Statistics}

In this study, $\mathrm{p}$ (significant) value was set to 0.05 . Table 5 reports the results of MANOVA.

Table 5 Results of MANOVA

\begin{tabular}{lllllll}
\hline Source & & SS & DF & MS & F & P \\
\hline $\mathbf{1}$ & Between Groups & 291.50 & 2 & 145.75 & 6,62 & $0.00^{*}$ \\
& Within Groups & 2003.61 & 91 & 22.02 & & \\
& Total & 2295.12 & 93 & & & \\
$\mathbf{2}$ & Between Groups & 141.47 & 2 & 70.74 & 3.20 & $0.05^{*}$ \\
& Within Groups & 2146.49 & 91 & 23.59 & & \\
$\mathbf{3}$ & Total & 2287.96 & 93 & & & \\
& Between Groups & 75.39 & 2 & 37.70 & 1.75 & 0.18 \\
& Within Groups & 1959.77 & 91 & 21.54 & & \\
& Total & 2035.16 & 93 & & & \\
\hline
\end{tabular}

1: Identification; 2:Terminology; 3: Comprehension

*Significant value $<=0.05$

From the results shown in Table 5, the effect of instructional treatment was found on two criterion tests (Identification test: $\mathrm{F}=6.62, \mathrm{p}=0.00<0.05$; Terminology test: $\mathrm{F}=3.00, \mathrm{p}=0.05<=0.05$ ).

Therefore, a follow-up comparison procedure, Tukey HDS, was performed with the results appearing in Table 6.

Table 6 Tukey HDS Analysis of MANOVA

\begin{tabular}{lcll}
\hline Source & Mean Difference & P \\
\hline $\mathbf{1}$ & Treatment 1 \& 2 & -3.23 & $0.02^{*}$ \\
& Treatment 1 \& 3 & -4.07 & $0.00^{*}$ \\
& Treatment 2 \& 3 & -0.84 & 0.76 \\
$\mathbf{2}$ & Treatment 1 \& 2 & -1.72 & 0.34 \\
& Treatment 1 \& 3 & -2.98 & $0.04^{*}$ \\
& Treatment 2 \& 3 & -1.26 & 0.57 \\
$\mathbf{3}$ & Treatment 1 \& 2 & -0.73 & 0.80 \\
& Treatment 1 \& 3 & -2.16 & 0.16 \\
& Treatment 2 \& 3 & -1.42 & 0.45 \\
\hline
\end{tabular}

1: Identification; 2:Terminology; 3: Comprehension

*Significant value $<=0.05$ 
From the results shown in Table 6 , in the identification test, statistically significant differences exist between Treatment 1 and Treatment $2(\mathrm{p}=0.02<0.05)$ and between Treatment 1 and Treatment $3(p=0.00<0.05)$. In the terminology test, a statistically significant difference exists between Treatment 1 and Treatment $3(\mathrm{p}=0.04<0.05)$. However, no significant differences were found in the comprehension test.

\section{Test of Research Hypothesis}

In summary, the results of MANOVA and Tukey HDS analysis show that significant differences were found among three treatment groups in the identification and terminology tests. The effect of instructional treatment indeed exists in this study. Therefore, the research hypothesis was rejected at 0.05 confidence level. Specifically, in the identification test, students in Treatment 2 (static visual scaffold) and Treatment 3 (interactive visual scaffold) performed better than Treatment 1 (control group). In the terminology test, Treatment 3 is superior to Treatment 1.

\section{Conclusions}

From the results of descriptive statistics, students in Treatment 3 performed better than other two treatment groups in three criterion tests. However, by transforming data into inferential statistics, Treatment 3 is only superior to Treatment 1 in the identification and terminology tests because significant differences were found between interactive visual scaffold (Treatment 3 ) and text-only instruction (Treatment 1). In the comprehension test, students in Treatment 3 did not outperform those in Treatment 1 or Treatment 2 . Therefore, during online reading process, especially for lower and medium order thinking (factual and conceptual knowledge), the interactive visual scaffold allows engineering students to receive more information in their minds. A possible explanation for this phenomenon is that animation effects in the interactive scaffolds did not develop the potential to support students' higher order thinking. Whether or not creating more animation effects in the interactive scaffolds may yield different results is worthy of further observation.

From the results of MANOVA, students in Treatment 2 performed better than Treatment 1 in the identification test. In other words, the static visual scaffold can also benefit engineering students' online learning. However, no significant difference was found between Treatment 2 and Treatment 3. Therefore, from a statistical perspective, static and interactive visual scaffolds can with equal effectiveness improve students' online reading abilities for lower order cognitive process (factual knowledge). A possible reason is that two visual scaffolds developed in this study all embedded static images, which share the same effect in the identification test.

This study confirmed the instructional effectiveness of varied visual scaffolds in facilitating different types of knowledge acquisition in an online reading environment. It is noted that because this study only used engineering students as a targeted group, the findings had limitations and cannot generalized into other learning settings. However, hypertext reading materials are main components for imparting instructional knowledge in Web-based settings. Online instructors or course designers may employ the characteristics of two visual scaffolds yielded in this study to engage in instructional design. Embedding those two visual scaffolds into online reading material can be an innovative teaching strategy.

Three recommendations for follow-up studies are proposed. First, future studies may examine the effect of individual differences (e.g. prior knowledge) on visual scaffolds in online learning environments. Whether or not individual differences may influence students' online reading performances is worthy of further investigation. Second, this study only tested the instructional effectiveness of two static visuals by using the science-oriented human heart. Future studies can integrate two static visuals into contents of different subjects (economics or English literature) in the hypertext environments. Last, participants' reading time may influence final results. Future studies 
may record student participants' reading time and analyze the interaction effect with visual scaffolds.

\section{Note}

This study is a continuation of a pilot study published in the Interdisciplinary Journal of Information, Knowledge, and Management.

\section{References}

Chen, W. F., \& Dwyer, F. M. (2003). Hypermedia research: Present and future. International Journal of Instructional Media, 30(2), 143-148.

Davis, J. D. (2007). Developing text for web-based instruction. In M. G. Moore, Handbook of distance education (2nd ed.) (pp. 285-294). Mahwah, NJ: Lawrence Erlbaum Associates.

Dwyer, F. M. (1978). Strategies for improving visual learning. State College, PA: Learning Services.

Dwyer, F. M. (2007). The program of systematic evaluation (PSE): Evaluating the effects of multimedia instruction 1965-2007. Educational Technology, 47(5), 41-45.

Hadwin, A. F., \& Winne, P. H. (2002). Conotes 2: A software tool for promoting self-regulation and collaboration. Educational Research \& Evaluation, 7(2), 331-334.

Hill, J. R., \& Hannafin, M. J. (2001). Teaching and learning in digital environments: The resurgence of resource-based learning environments. Educational Technology Research and Development, 49(3), $37-52$.

Nitko, A. J., \& Brookhart, S. M. (2006). Educational assessment of students (5th ed.). Upper Saddle River, NJ: Prentice-Hall Inc.

Norman, D. A. (2004). Emotional design: Why we love (or hate) everyday things. NY: Basic Books.

Puntambekar, S., \& Hubscher, R. (2005). Tools for scaffold students in a complex learning environment: What have we gained and what have we missed? Educational Psychologist, 40(1), 1-12.

Saye, J. W., \& Brush, T. (2002). Scaffold critical reasoning about history and social issues in multimedia-supported learning environments. Educational Technology Research and Development, 50(3), 77-96.

Sharma, P., \& Hannafin, M. J. (2007). Scaffold in technology-enhanced learning environments. Interactive Learning Environments, 15(1), 27-46.

Sharma, P., Oliver, K. M., \& Hannafin, M. J. (2007). Teaching and learning in directed environments. In M. G. Moore, Handbook of distance education ( $2^{\text {nd }}$ ed.) (pp. 259-270). Mahwah, NJ: Lawrence Erlbaum Associates.

Wood, D., Bruner, J. S., \& Ross, G. (1976). The role of tutoring in problem solving. Journal of Child Psychology \& Psychiatry \& Allied Disciplines, 17(2), 89-100.

Yoder, E. P. (2008). Applied statistic analysis. State College, PA: The Pennsylvania State University.

Zumbach, J., Reimam, P., \& Koch, S.C. (2006). Monitoring students' collaboration in computer-mediated collaborative problem-solving: Applied feedback approaches. Journal of Educational Computing Research, 35(4), 399-424. 


\section{Biographies}

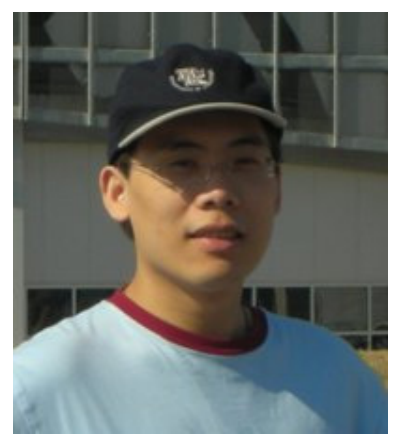

Pao-Nan Chou is a post-doctoral fellow in the Research Lab of Engineering \& Technology Education at Cheng Shiu University. He received his B.S. in Electronic Engineering \& Computing Education and M.S. in Workforce Education \& Development from National Taipei University of Technology, Taiwan. He also received his M.Ed. and Ph.D. in Instructional Systems from The Pennsylvanian State University, USA. His research interests include e-learning and engineering education.

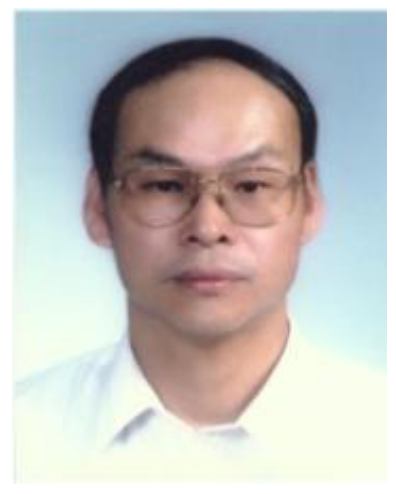

Hsi-Chi Hsiao is the director in the Research Lab of Engineering \& Technology Education and chair professor in the Graduate Institute of Business Administration at Cheng Shiu University. He received his B.S. in Industrial Technology \& Education from National Taiwan Normal University, Taiwan. He also received his M.Ed. in Industrial Education from The University of Wisconsin, USA and Ph.D. in Curriculum \& Instruction from The Indiana State University, USA. His research interests include human resource development and management, and engineering education. 